\title{
The Potential of Remaining Oil and Exploration Methods of the Second Class Reservoir
}

\author{
LiHua Ma \\ The third oil production plant, Daqing Oilfield Company Ltd, Daqing,163412,China \\ Malihuaxing@126.com
}

\begin{abstract}
Keywords: Remaining Oil; Fault; Lateral Accretion; Intered; Cyclic Flooding; Profile Control;Tapping Potential

Abstract. Based on the analysis of the formation of the residual oil in the area, combined with the fine geological and multidisciplinary research results, summed up the main types of remaining oil, combined with dynamic and static data, used some measures such as cyclic flooding, fracturing, profile control, to tap the potential of remaining oil, and achieved good results.
\end{abstract}

\section{Influencing factors of remaining oil formation}

The Plane Phase Change is Obvious, and There are Some Residual Oil. The layers of the second reservoir group, mainly in the meandering river sandbodies, have the main channel (point bar), abandoned channel, crevasse channel and interchannel sand microfacies[1-2]. Because of the large change of sand body size, the sedimentary microfacies in the plane are obviously different, and the injected water can not be displaced to the sand body and the edge of the river. At the same time, due to the development of abandoned river channel, the formation of an independent lens, the remaining oil also play a role in shielding.

The Reservoir Structure is Complex, and the Remaining Oil Potential is Big. The research of the thick oil layer structure and remaining oil shows that the reservoir of this region has layer of interlayers and point bar inside accretion, and reservoir heterogeneity is obvious. these factors led to the formation of internal uneven use (Table 1), has a certain potential of remaining oil[3-4].

TABLE 1. Water flooded condition in oil layer (well count: 164)

\begin{tabular}{|c|c|c|c|c|}
\hline \multirow{2}{*}{$\begin{array}{c}\text { Effective Thickness } \\
\text { Classification }\end{array}$} & \multicolumn{4}{|c|}{ Ratio of water flooded layer } \\
\cline { 2 - 5 } & High Water Flooded & $\begin{array}{c}\text { Moderate } \\
\text { Flooded }\end{array}$ & $\begin{array}{c}\text { Low Water } \\
\text { Flooded }\end{array}$ & Not Flooded \\
\cline { 2 - 5 } & Effective Thickness(\%) & $\begin{array}{c}\text { Effective } \\
\text { Thickness(\%) }\end{array}$ & $\begin{array}{c}\text { Effective } \\
\text { Thickness(\%) }\end{array}$ & $\begin{array}{c}\text { Effective } \\
\text { Thickness(\%) }\end{array}$ \\
\hline$\geq 2.0 \mathrm{~m}$ & 47.30 & 33.78 & 16.82 & 2.10 \\
\hline $2.0 \sim 1.0 \mathrm{~m}$ & 32.02 & 40.26 & 24.48 & 3.25 \\
\hline $1.0 \sim 0.5 \mathrm{~m}$ & 17.28 & 44.12 & 31.6 & 7.01 \\
\hline$<0.5$ & 3.30 & 41.00 & 41.46 & 14.24 \\
\hline Total & 37.84 & 37.17 & 21.62 & 3.37 \\
\hline
\end{tabular}

Because of the Development of Fault , Injection Production Relationship is not Perfect. The faults of the region develope well ,such as 76\#, 78\#, 781\# fault. These are normal faults, and the fault distance and extension distance are long, so the injection production relationship around the fault is not perfect. And injection producer ratio is $1: 2$, thus forming the phenomenon-"theproduction well much more than the injiection well" in fault zone, seriously affecting the development of the effect of residual oil in this area are not fully tapping.

The analysis about types of the remaining oil. Due to the influence of the plane phase transition, the structure of the oil reservoir and the fault, the remaining oil is relatively enriched: 
The Type of the Remaining Oil on Plane. The first is the residual oil of fault block: due to the influence of the fault, the injection is less, so the injection production is not perfect or the injection production well distance is far from the water injection effect, and the remaining oil is formed.

The second is the remaining oil in the stagnant zone: affected by the five point area well pattern, the injected water can not displace to the area near the center line of the two injection wells.

The third is the local variation position and channel edge of residual oil: because the main sand near the channel and outer edge of the edge table, poor physical properties of single sand, water and liquid production capacity is low, the use of poor. At the same time because of the narrow lead to imperfect injection production, the formation of remaining oil[5-7].

The Type of Remaining Oil within the Layers. The first is the interlayer type: the segmentation effect of lateral accretion, the upper interlayer remaining oil is mainly distributed in the top of the meandering river point bar sand body.

The second is the residual oil type: due to the interaction of rhythm by positive rhythm and dissection, the formation of positive rhythm of residual oil in thick oil layer; due to the differences in layer heterogeneity, poor physical property, rhythm section top and sandwich near the presence of a small amount of residual oil distribution sheet type (Fig. 1).

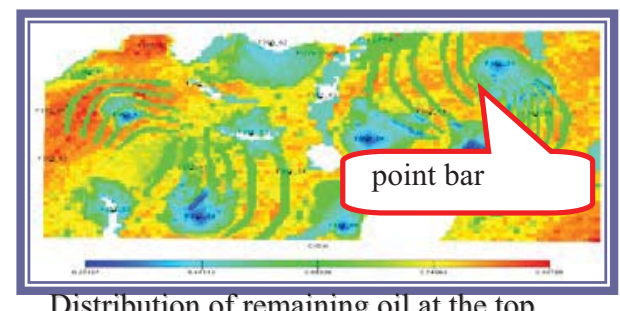

Distribution of remaining oil at the top

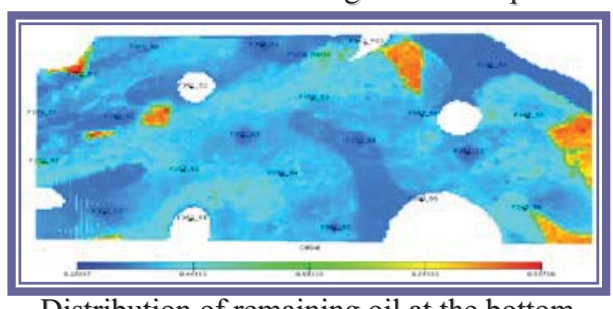

Distribution of remaining oil at the bottom

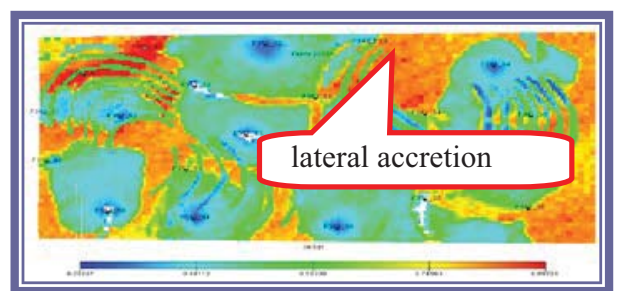

Distribution of remaining oil in the middle

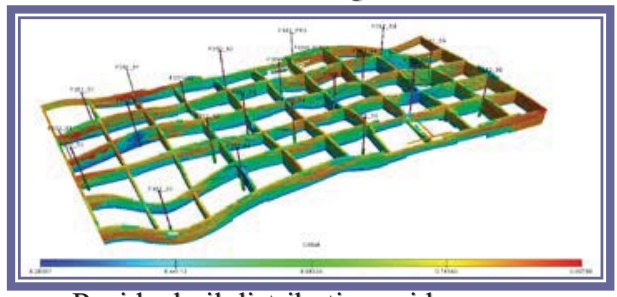

Residual oil distribution grid map

FIGURE 1. Sketch map of remaining oil distribution in reservoir

\section{The tapping method of remaining oil}

According to the characteristics of remaining oil distribution in this area, explore and research the corresponding methods of the remaining oil, and achieved good results.

Cyclic Flooding can Excabate the Remaining Oil of the Top of Thick Oil Reservoir and the Remaining Area. The remaining oil is the rhythm and the gravity function formed at the top of thick oil layer characteristics, through the implementation of periodic flooding, high permeability section water, boost fast, low permeability section high pressure ratio, water inflow in low permeability reservoir in the additional pressure difference; stop injection, high pressure permeability section reduction will be lower than the low permeability layer of the pressure, so that part of the oil reservoir with low permeability in additional pressure in the reverse effect flows back to the high permeability layer after recovery. At the same time, after the cyclic flooding, the flow direction is changed by the periodic change of the flow field in the oil layer, and the volume of the residual oil is effectively utilized.

According to the principle of cyclic flooding, combined with reservoir development and test data, select 4 injection wells to carry out cyclic flooding which have the well developed reservoir, high water flooded degree and positive rhythm , take the principle of well injection to further excavate remaining oil. The half period of cycle water injection was 50 days, and the daily water injection rate was recovered by the ratio of $70 \%$. After the implementation of the 4 oil wells production fluid 
stability, the initial increase by $4.6 \mathrm{t}$, water decreased by $1.3 \%$, the peak period of increasing oil is $17 \mathrm{t}$, water content decreased by 4.8 percentage points, valid for a period of 20 months.

Select the Preferred Fracturing Method to Excavate Remaining Oil in Local Variation and the River Edge. According to the characteristics of different types of oil reservoirs, this paper combines the research results of Fine Geology and residual oil to optimize the fracturing method and to explore the remaining oil. The oil water content is low, the interlayer conditions can form a separate layer fracturing, using common fracturing; fracturing layer on adjacent segment and high water flooded layer, the interlayer is less than 2 meters, the conventional methods can not meet the single card in the interlayer fracturing, greater than 0.8 meters, the thin layer fracturing of fractured layer, interlayer; thin, not a single card layer with multi fracturing; by optimizing fracturing, fracturing oil wells 18, after fracturing the daily oil increases 5.8t, comprehensive water cut down 4 percentage points. The thin layer fracturing in $6 \mathrm{wells}$, daily oil of single well is $7.1 \mathrm{t}$, water content decreased by 6.7 percentage points; the common pressure large displacement of 4 wells, daily oil of single well is $6.2 \mathrm{t}$, water content decreased by 1.6 percentage points; multi fracturing in 5 wells, daily oil of single well is $5.0 \mathrm{t}$, water content decreased by 0.3 percentage points; the common pressure 3 wells, daily oil of single well is $4.1 \mathrm{t}$..

Optimize the Profile Control Scheme to Excavate the Positive Rhythm Type of Remaining Oil. Using the principle in which the profile control agent for plugging high permeable layer channels to improve the water absorption status of the low permeability layers, select 6 injection wells to implement profile control, which have the large scale sand body ,serious flooding, positive rhythm and the remaining oil on the top of the thick oil layer mainly. By optimizing the profile control scheme, three slugs were used to obtain better results. At present, the oil production of the oil wells in the surrounding area increase by $18.3 \mathrm{t}$, and the water content decrease by 2.2 percentage points.

Use the Implementation of the Sub Layer Injection Production and Strengthen Injection in the Direction of the Reverse Side of the Interlayer to Excavate the Remaining Oil. In order to improve the producing degree in thick oil layers and improve the contradictions within the layer, on the basis of thick oil reservoir internal structure research, sandwich tracking are used and layer subdivision injection production is implemented in the layers with horizon interlayer in the layer. Water flooding control the lower segment, strengthen the upper low flooding period, and increase the thick oil the producing degree of inner layer. In the implementation of the subdivision water injection wells, injection pressure of 8 wells increased by $0.9 \mathrm{MPa}$. Within the subdivision of the production of 2 wells, daily production fluid drop 92t, daily oil increase; by $1.5 \mathrm{t}$, and water content decrease by 4 percentage points.

Study on the internal structure of thick layer showed that in some layers point bar developed, lateral accretion interlayer, lateral direction from west to East, due to lateral accretion, forming the remaining oil of lateral accretion interlayer type. The tracer test reflected parallel to lateral direction injection forward speed, based on simulation results, take the inverse lateral direction parallel to lateral direction, strengthen the control of mined for potential, adjustment of 10 injection wells , injection intensity of $6.4 \mathrm{~m} 3 / \mathrm{d} \cdot \mathrm{m}, 2.2 \mathrm{~m} 3 / \mathrm{d} \cdot \mathrm{m}$ higher than the other direction. The daily oil of single well of 12 oil wells around injection wells increase by $0.9 \mathrm{t}$, comprehensive water cut by 1 percentage points.

Control the Adjustment of Injection Wells to Improve the Injection Production Status of the Fault Zone. Well seismic joint research results show that the newly discovered $781 \#$ derived small fault 78 \# fault zone of the tail, to verify the fault shows that the pulse test: well A and well B both in the north side of the fault adjoin; The wells are not connected on both sides of the fault such as well C and well A, connectivity has certain shielding effect the reservoir, resulting in injection production relationship is not perfect. In view of this situation, combined with the fine geological research results, the dynamic monitoring data were used to adjust the injection wells in this area. At the same time, wells in the area of exploration on optimization, perfect injection production relationship. 


\section{Several understanding}

(1) Residual oil in thick oil layers of extra high water cut stage is difficult to tap;

(2) Layer subdivision, cyclic flooding and profile control are effective means of tapping the remaining oil in thick oil layer;

(3) The optimization of fracturing is the key to the fracturing of different types of reservoirs.

\section{References}

[1]. Xu Jianjun, Xu Yan-chao, Yan, Li-me,et.al. Research on the method of optimal PMU placement. International Journal of Online Engineering,v9, S7, p24-29, 2013

[2]. Xu Jian-Jun, Y. Y. Zi., Numerical Modeling for Enhancement of Oil Recovery via Direct Current. International Journal of Applied Mathematics and Statistics，2013，43（13）: 318-326

[3]. Longchao, Zhu Jianjun, Xu; Limei, Yan. Research on congestion elimination method of circuit overload and transmission congestion in the internet of things. Multimedia Tools and Applications, $\mathrm{p}$ 1-20, June 27, 2016

[4]. Yan Limei, Zhu Yusong, Xu Jianjun,et.al. Transmission Lines Modeling Method Based on Fractional Order Calculus Theory. TRANSACTIONS OF CHINA ELECTROTECHNICAL SOCIETY, 2014 ,Vol.29,No. 9:260-268 (In Chinese)

[5]. YAN Li-mei, CUI Jia, XU Jian-jun,et.al. Power system state estimation of quadrature Kalman filter based on PMU/SCADA measurements. Electric Machines and Control. 2014, Vol.18 No.6,: 78-84. (In Chinese)

[6]. YAN Limei,XIE Yibing, XU Jianjun, et.al. Improved Forward and Backward Substitution in Calculation of Power Distribution Network with Distributed Generation. JOURNAL OF XI'AN JIAOTONG UNIVERSITY,2013, Vol.47, No.6, p117-123. (In Chinese)

[7]. Xu J.J., Gai D., Yan L.M. A NEW FAULT IDENTIFICATION AND DIAGNOSIS ON PUMP VALVES OF MEDICAL RECIPROCATING PUMPS. Basic \& Clinical Pharmacology \& Toxicology, 2016,118 (Suppl. 1), 38-38 